\title{
Role of Interfacial Dislocations on Creep of a Fully Lamellar TiAl
}

\author{
T.G. Nieh \\ L.M. Hsiung
}

This paper was prepared for submittal to the 8th International Conference on Creep and Fracture of Engineering Materials and Structures

Tsukuba City, Japan

November 1-5, 1999

August 16, 1999

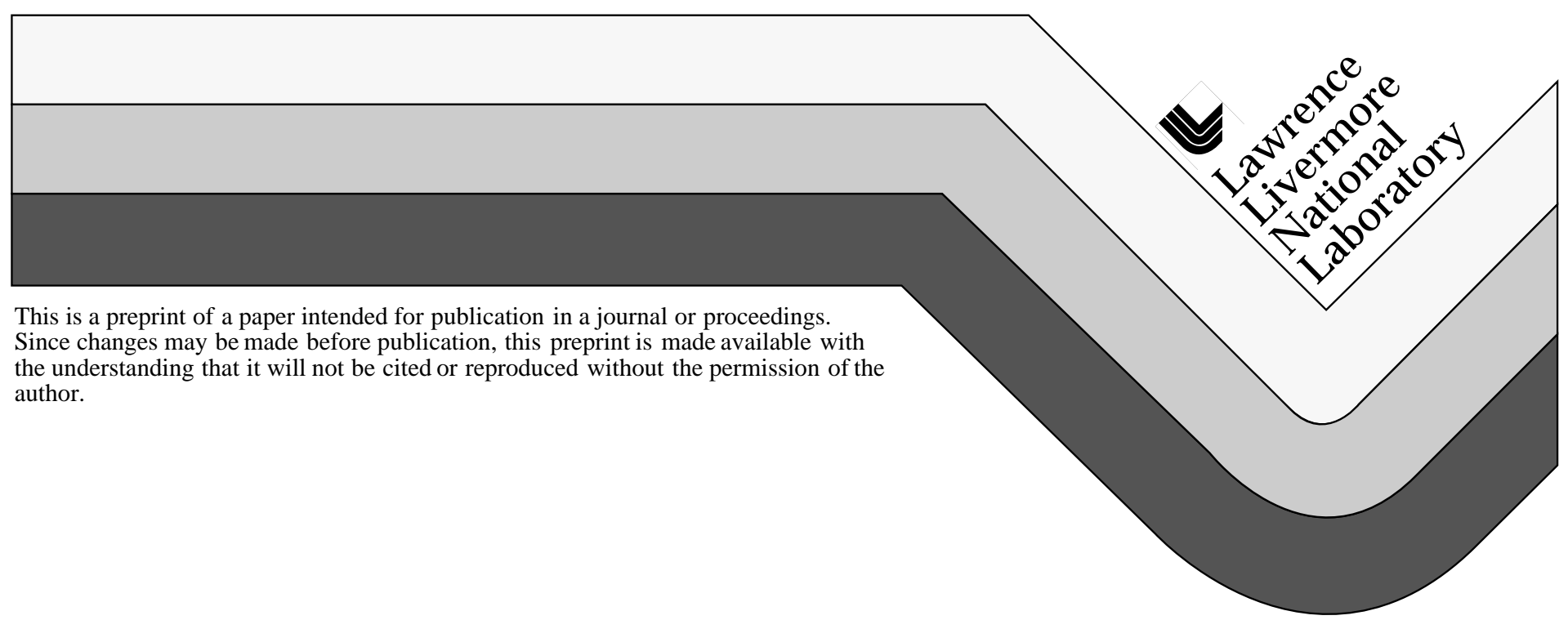




\section{DISCLAIMER}

This document was prepared as an account of work sponsored by an agency of the United States Government. Neither the United States Government nor the University of California nor any of their employees, makes any warranty, express or implied, or assumes any legal liability or responsibility for the accuracy, completeness, or usefulness of any information, apparatus, product, or process

disclosed, or represents that its use would not infringe privately owned rights. Reference herein to any specific commercial product, process, or service by trade name, trademark, manufacturer, or otherwise, does not necessarily constitute or imply its endorsement, recommendation, or favoring by the United States Government or the University of California. The views and opinions of authors expressed herein do not necessarily state or reflect those of the United States Government or the University of California, and shall not be used for advertising or product endorsement purposes. 


\title{
Role of Interfacial Dislocations on Creep of a Fully Lamellar TiAl
}

\author{
T. G. Nieh and L. M. Hsiung \\ Lawrence Livermore National Laboratory, L-350, P.O. Box 808, Livermore, CA 94551, U.S.A.
}

Keywords: intermetallic alloy, creep, interface, interface sliding, deformation twinning, laminate, dislocation pileup,

\begin{abstract}
Deformation mechanisms of a fully lamellar TiAl ( $\gamma$ lamellae: $100 \sim 300 \mathrm{~nm}$ thick, $\alpha_{2}$ lamellae: $10 \sim 50 \mathrm{~nm}$ thick) crept at $760^{\circ} \mathrm{C}$ have been investigated. It was found that, as a result of a fine structure, the motion and multiplication of dislocations within both $\gamma$ and $\alpha_{2}$ lamellae are limited at low creep stresses $(<400 \mathrm{MPa})$. Thus, the glide and climb of lattice dislocations have insignificant contribution to creep deformation. In contrast, the motion of interfacial dislocations on $\gamma / \alpha_{2}$ and $\gamma / \gamma$ interfaces (i.e. interface sliding) dominates the deformation at low stresses. The major obstacles impeding the motion of interfacial dislocations was found to be lattice dislocations impinging on lamellar interfaces. The number of impinging lattice dislocations increases as the applied stress increases and, subsequently, causes the pileup of interfacial dislocations on the interfaces. The pileup further leads to the formation of deformation twins. Deformation twinning activated by the pileup of interfacial dislocations is suggested to be the dominant deformation mechanism at high stresses $(>400 \mathrm{MPa})$.
\end{abstract}

\section{Introduction}

Two-phase [TiAl $(\gamma)-\mathrm{Ti}_{3} \mathrm{Al}\left(\alpha_{2}\right)$ ] TiAl alloys have recently attracted more attention than single-phase $\gamma$-TiAl alloys because of their superior combination of room-temperature mechanical properties. Great efforts have been made to improve the creep resistance of two-phase TiAl alloys through alloy design and microstructural optimization. By controlling thermomechanical treatments, three different types of microstructures [equiaxed, duplex, and fully lamellar $(F L)$ ] have been developed [1]. It is well known that the creep resistance of two-phase alloys with a $F L$ microstructure is better than that of the alloys with equiaxed and/or duplex microstructures [1-4]. Also, the creep resistance of powder metallurgy $F L$-TiAl alloys is superior to that of ingot metallurgy $F L$-TiAl alloys as a result of a refined lamellar microstructure [2]. Although a significant progress has been made in improving the creep resistance of TiAl alloys, little is known about the underlying creep mechanisms. Several studies on the creep behavior of $F L-T i A l$ alloys have been made $[3,5]$, only a few of the creep models have considered the contribution of interface sliding. The motion of interfacial dislocations was recently demonstrated to play an important role during the creep of FL-TiAl [6-8].

In a manner similar to other TiAl alloys, creep of fully lamellar $F L$-TiAl alloys revealed two distinct regimes, i.e. low stress $(L S)$ and high stress $(H S)$, as shown in Fig. 1 [8]. A nearly linear creep behavior was observed in the $L S$ regime $(<400 \mathrm{MPa})$, i.e. $\dot{\varepsilon}=\mathrm{K} \cdot \sigma^{n}$ and $n=1.2 \sim 1.6$, and a 
power-law creep behavior with $n=6.7 \sim 10.1$ in the $H S$ regime ( $>400 \mathrm{MPa}$.). An apparent activation energy $Q$ of $160.4 \mathrm{~kJ} / \mathrm{mole}$ was also obtained [8]. This value is much lower than the activation enthalpy $\left(\mathrm{Q}_{\mathrm{v}}=295 \mathrm{~kJ} / \mathrm{mole}[9,10], 330 \mathrm{~kJ} / \mathrm{mole}[11]\right)$ for lattice diffusion of Ti in $\gamma$ TiAl. However, it is close to the activation enthalpy for diffusion of $\mathrm{O}$ in $\gamma$-TiAl $(177 \mathrm{~kJ} / \mathrm{mole})$ [12], $\mathrm{O}$ in $\mathrm{Ti}(168 \mathrm{~kJ} / \mathrm{mole})$ [13], $\mathrm{O}$ in Ti-6Al-4Zr-2Mo-2Sn (167.2 kJ/mole) [14], and $\mathrm{C}$ in $\mathrm{Ti}$ $(127.6 \mathrm{~kJ} / \mathrm{mole})[15]$. Also, the value is also close to the activation enthalpy for dislocation core diffusion $\left(\mathrm{Q}_{\mathrm{c}} / \mathrm{Q}_{\mathrm{v}} \approx 0.6\right.$, i.e. $\left.177 \sim 198 \mathrm{~kJ} / \mathrm{mole}\right)$. This result indicates that the dislocation climb assisted by lattice diffusion within $\gamma$ laths is probably not responsible for the creep deformation of refined FL-TiAl at low applied stresses. The purpose of the present investigation is to correlate creep behavior with deformation (interfacial) substructure to elucidate further the creep mechanisms of refined FL-TiAl.

\section{Experimental}

A FL-TiAl alloy with a nominal composition: Ti-47Al-2Cr-2Nb (in at. \%) was used for this study. The alloy was fabricated by a hot-extrusion of gas-atomized titanium aluminide powder at $1400^{\circ} \mathrm{C}$. The interstitial impurities [in parts per million (ppm) by weight] of the alloy are O: 780; $\mathrm{N}: 40 ; \mathrm{C}: 260$. Test specimens with a gauge dimension of $24.4 \times 5.08 \times 1.52 \mathrm{~mm}$ were prepared from the annealed alloy by electrical discharge machining. Creep tests were conducted in a deadload creep machine with a lever arm ratio of 16:1. Tests were performed in air in a split furnace with three zones at $760^{\circ} \mathrm{C}$. Detail information regarding the creep experiment and experimental data was reported elsewhere [2,8]. For current study, the deformation substructures of two tested specimens [one crept at a stress of $138 \mathrm{MPa}$ (creep strain: $\sim 0.25 \%$ ) in the $L S$ regime, and the other crept at a stress of $518 \mathrm{MPa}$ (creep strain: $~ 3.6 \%$ ) in the $H S$ regime] were investigated. TEM foils were prepared by twin-jet electropolishing in a solution of $60 \mathrm{vol} . \%$ methanol, $35 \mathrm{vol}$. \% butyl alcohol and 5 vol. \% perchloric acid at $\sim 15 \mathrm{~V}$ and $-30^{\circ} \mathrm{C}$. The microstructures of the crept alloys were examined using a JEOL-200CX transmission electron microscope equipped with a double-tilt goniometer stage. Images of dislocations were recorded using a weak-beam dark field (WBDF) imaging technique under $g(3 g)$ diffraction conditions.

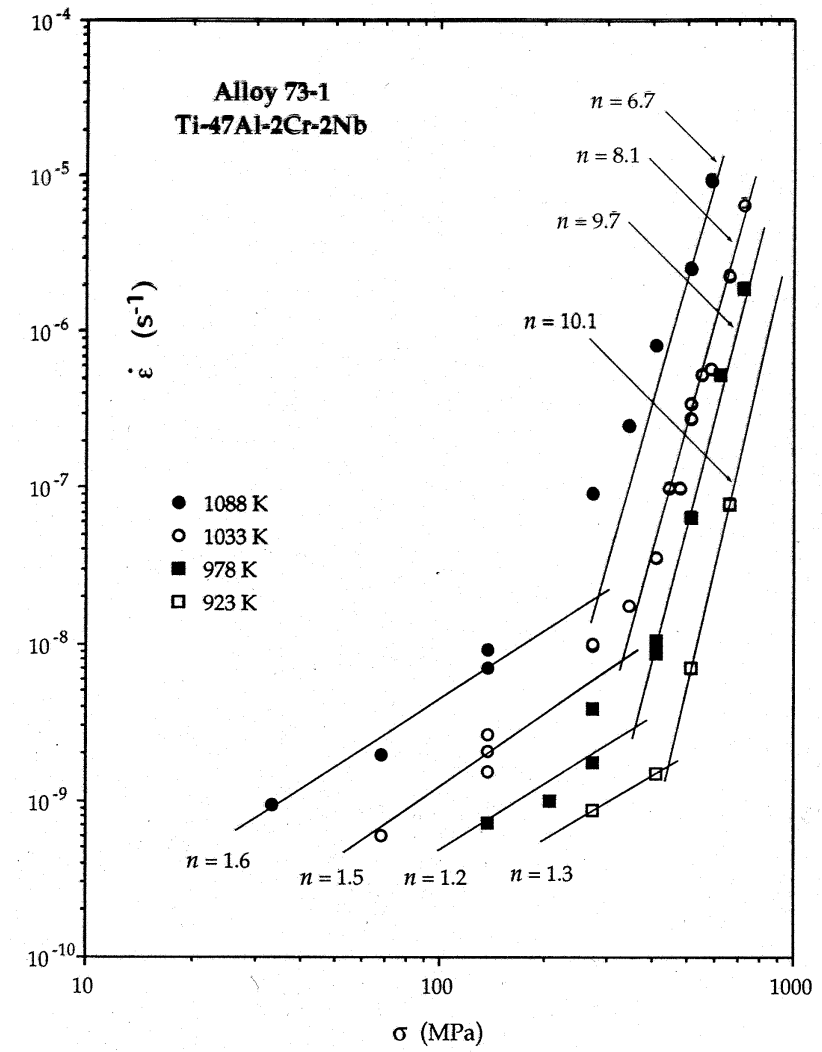


Fig. 1 Plots of steady state creep rates versus applied stress at testing temperatures between 650 and $815^{\circ} \mathrm{C}[8]$.

\section{Results and discussion}

\section{Microstructure of As-Fabricated Alloy}

A typical edge-on lamellar microstructure of the as-fabricated alloy is shown in Fig. 2 (left). The thicknesses of lamellae were measured to be in the range of $100 \sim 300 \mathrm{~nm}$ and $10 \sim 50 \mathrm{~nm}$ for $\gamma$ and $\alpha_{2}$, respectively. A WBDF image showing the dislocation substructure of the alloy is shown in Fig. 2 (right). Both lattice dislocations ( $L D$ hereafter), formed within $\gamma$ lamellae, and interfacial dislocations (ID hereafter), formed on lamellar interfaces, can be readily seen. Evidently, the population of $I D$ is much greater than that of $L D$. Here, $L D$ includes both threading dislocation (i.e. dislocation terminates on the lamellar interfaces) and free dislocation (i.e. dislocation which is physically distant from the lamellar interfaces). It is noted that the density of threading dislocation is greater than that of free dislocation.
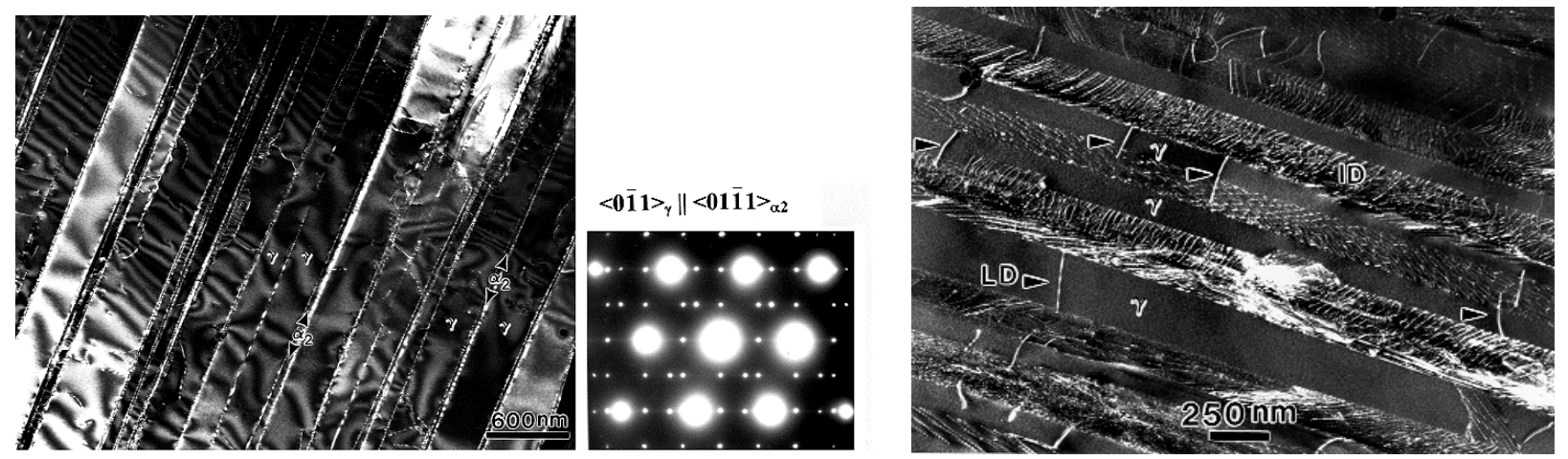

Fig. 2 Dark-field images showing typical dislocation substructures observed from an as-fabricated alloy sample; (left) edge-on view, and (right) tilt view.

\section{Creep Deformation in the Low Stress $(L S)$ regime}

Deformation in a lamellar alloy is, in principle, caused by the multiplication and motion of $I D$ and $L D$. Since $\alpha_{2}$ is stronger than $\gamma$, and also the volume fraction of $\alpha_{2}$ lamella is small $(\leq 10 \%)$, deformation by the motion of $L D$ is expected to occur mainly in the $\gamma$ lamellae. Furthermore, due to the short moving distance of free dislocations the motion (bowing) of threading dislocations contributes primarily to deformation within the $\gamma$ lamellae. In general, an applied shear stress must exceed the critical resolved shear stress in order to bow the threading dislocations. The critical resolved shear stress $\left(\tau_{b} \approx \mu b / d\right)$ is dependent upon the thickness $(d)$ of $\gamma$ lamellae. Taking $\mu=59$ $\mathrm{GPa}\left(\right.$ at $\left.760^{\circ} \mathrm{C}\right), b=0.28 \mathrm{~nm}$, and $d=100 \sim 300 \mathrm{~nm}$, the critical resolved shear stress is calculated to be $\tau_{b}=55 \sim 165 \mathrm{MPa}$. Thus, the applied stress $\left(\sigma \approx 2 \tau_{b}\right)$ required to bow the threading dislocations is estimated to be greater than $110 \sim 330 \mathrm{MPa}$. Taking into account the fact that the motion and multiplication of $L D$ in both $\gamma$ and $\alpha_{2}$ lamellae are limited in the $L S$ regime, as a result of the refined lamellae, the motion of pre-existing $I D$ is expected to become important to deformation. It is worth noting that the cooperative motion of $I D$ in $F L$-TiAl deformed at room temperature has been observed previously in an in situ straining experiment [7]. We now present an indirect evidence of the motion of $I D$ in FL-TiAl creep deformed at $760^{\circ} \mathrm{C}$.

The interfacial substructure of a soft lamellar grain (oriented nearly $\sim 45^{\circ}$ with respect to the stress axis) in a sample crept at $138 \mathrm{MPa}$ is shown in Fig. 3 (left). The appearance of fringe contrasts trailing along $I D$ can be readily observed. The fringe contrasts can be best viewed when $2 \pi \boldsymbol{g} \cdot \boldsymbol{R}=2 / 3$ or $4 / 3$, where $\boldsymbol{g}$ is the reflection vector and $\boldsymbol{R}(=1 / 3[111])$ is the displacement vector of stacking fault in $\gamma$ lamella; this suggests the formation of stacking faults on the wake of $I D$. The triangular features are presumably formed by the motion of three sets of $I D$ arrays with Burgers 


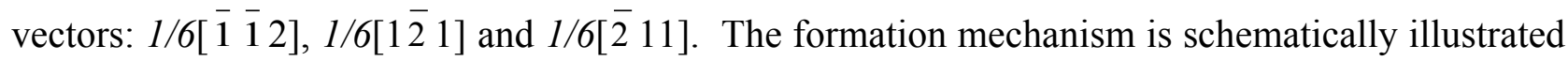
in Fig. 3 (right), where the equilibrium $\gamma / \alpha_{2}$ interface resulted from both $I D$ motion (pure shear) and chemical diffusion is lagging behind the non-equilibrium interface created solely by the motion

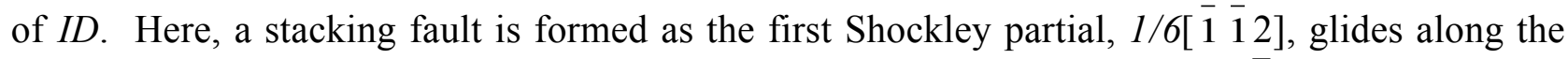
interface, but is terminated by the glide of the second Shockley partial, $1 / 6[1 \overline{2} 1]$. Then, another stacking fault is formed as the third Shockley partial, $1 / 6[\overline{2} 11]$, glides along.
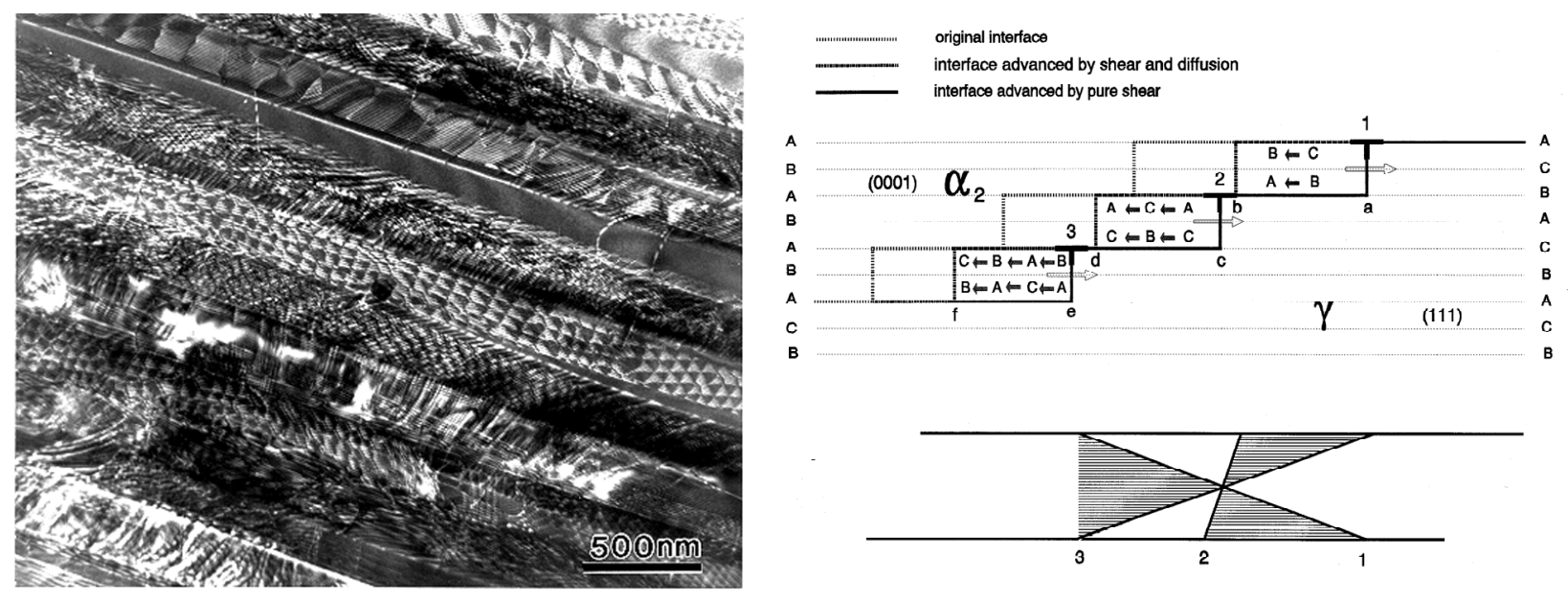

Fig. 3 (left) A WBDF image showing the appearance of fringe contrast trailing along ID on $\gamma / \alpha_{2}$ and $\gamma / \gamma$ interfaces, (right) a schematic illustration of the migration of $\gamma / \alpha_{2}$ interface resulted from the cooperative motion of $I D$ and chemical diffusion. Notice that the equilibrium interface is lagging behind the non-equilibrium interface generated by a pure shear. The triangular fault ribbons resulted from the motion of three different Shockley partials are also illustrated. The letters $\mathrm{A}, \mathrm{B}$ and $\mathrm{C}$ stand for the stacking sequence.

It is noted that the highly populated $I D$ and stacking faults on lamellar interfaces are expected to be the preferential sites for solute or impurity segregation. In fact, experimental evidence of solute segregation to $\gamma / \alpha_{2}$ and $\gamma / \gamma$ interfaces has recently been reported [16]. These solute segregants can act as short-range barriers for the motion of $I D$, in a manner similar to that of Cottrell atmosphere and Suzuki effect [17]; this results in the viscous glide of ID. The steady state creep rate may be described using the Orowan equation given below:

$\dot{\varepsilon}=\Phi \rho_{m} b \bar{v}$

where $\Phi$ is a geometrical factor (for isotropic polycrystals: inverse of Taylor factor, for single crystal: Schmid factor), $\rho_{m}$ is the density of mobile dislocations, $b$ is the Burgers vector, and $\bar{v}$ is the average dislocation velocity. Since the multiplication of lattice dislocations within refined $\gamma$ and $\alpha_{2}$ lamellae is very limited when the material is deformed at low stress, the glide of preexisting $I D$ arrays becomes the predominant deformation mechanism. That is, the mobile dislocation density $\left(\rho_{m)}\right.$ is approximately equals to the density of $I D$. Under small creep-strain, low creep stress and strain-rate, it is plausible to assume that $I D$ arrays are moving with a constant spacing so that the density of mobile dislocations is insensitive to the applied stress, i.e. $\rho_{m} \neq \mathrm{F}(\sigma)$. Accordingly, the steady state creep rate $(\dot{\varepsilon})$ is mainly controlled by the average velocity $(\bar{v})$ of $I D$ arrays [i.e. $\dot{\varepsilon}=\mathrm{F}(\bar{v})$ ], which are considered to be drifting with the pinning solute (impurity) atoms at low applied stresses.

Let there be $m$ solute atoms per unit length of dislocation line which effectively pin a dislocation line. When a unit length of $L D$ drifts one atomic distance under an external stress $\sigma$, the estimated drift velocity of the dislocation line is of the order $[17,18]$ : 
where $v\left(\sim 10^{12} / \mathrm{sec}\right)$ is the average vibration frequency of the dislocation line, $S$ is the entropy of activation for the motion, and $Q$ is the activation energy associated with the jump of a pinning atom. It is seen that the average dislocation velocity is linearly proportional to the applied stress. Consequently by combining Eqs. (1) and (2), a linear creep behavior [i.e. $\dot{\varepsilon} \propto \sigma^{n} \exp (-Q / k T)$, where $n=1$ ] is predicted provided all the mobile dislocations located on the interfaces are pinned by solute (impurity) atoms and no dislocation multiplication takes places. The slight deviation of $n$ values from unity may be caused by dislocation multiplication on interface occurred as a result of dislocation pile-up [6,7], this event is expected to become more significant as creep strain and applied stress increase. For example, the stress due to a pile-up of $n$ dislocations at a distance $\lambda$ from the head of the pile-up is given approximately by $[17,19]$ :

$\sigma=\mu n b / \pi \eta \lambda$

where $\eta=1$ or $1-v$ for screw or edge dislocation, respectively. Since $n / \lambda \approx \rho_{m}$, thus

$\rho_{m} \approx \pi \eta \sigma / \mu b$

That is, when pile-up occurs, $\rho_{m}=f(\sigma)$, and the dislocation density proportionally increases with increasing shear stress. By inserting Eqs. (2) and (4) into Eq. (1), thus $\dot{\varepsilon} \propto \sigma^{2} \exp (-Q / k T)$, i.e. $n=$ 2 is obtained. Thus, the slight deviation of $n$ from unity may be attributable to occurrence of local dislocation pile-up during the motion of interfacial dislocations at applied stresses $<400 \mathrm{MPa}$. In summary, the nearly linear relationship between strain rate and stress, and the fact that the activation energy is close to that for impurity or solute diffusion suggest that viscous glide of interfacial dislocations is the dominant deformation mechanism at low applied stresses.

\section{Creep Deformation in the High Stress $(H S)$ Regime}

During the sliding of lamellar interfaces, the glide of $I D$ is mainly impeded by impinged $L D$. A typical example is shown in Fig. 4. Here, a dislocation network formed by the reaction between impinged $L D$ and intrinsic $I D$ can be readily observed on a $\gamma / \alpha_{2}$ Interface. Also noted is the mobility of $I D$ suddenly decreases at site $\mathrm{C}$ and results in dislocation pileup. The occurrence of $L D$ impingement on lamellar interfaces is expected to increase when the applied stress increases, i.e. more dislocation pileups would be formed at higher applied stresses.

Deformation twinning was found to be an important deformation mechanism when the alloy was creep deformed at stresses greater than $400 \mathrm{MPa}$. An example is given in Fig. 5 (left). Here, the (111) [211]-type deformation twins (DT hereafter) formed within $\gamma$ lamellae in a specimen crept at $518 \mathrm{MPa}$. It is noted that one of the twin lamellae was still growing between two lamellar interfaces, and its growth would be eventually terminated by the lower interface. This observation suggests that lamellar interfaces are preferred nucleation sites for $D T$, presumably resulting from the high local stresses caused by the pileup of $I D$. That is, deformation twinning in FL-TiAl is a result of stress relaxation along the interfaces $[6,20,21]$.

The stress concentration $\left(\tau_{e}\right)$ at the tip of the pileup of $n$ dislocations can be estimated by $\tau_{e}=n \tau_{i}$, where $\tau_{i}$ is the resolved shear stress acting on the lamellar interface. To relieve the stress concentration, the (111)-type twins are nucleated from the interface by successive dissociation reaction of $I D: 1 / 6[\overline{1} 2 \overline{1}]_{(111)} \rightarrow 1 / 6[011]_{(100)}+1 / 6[\overline{1} 1 \overline{2}]_{(111)}$. This dislocation reaction for twinning is schematically illustrated in Fig. 5 (right), where $1 / 6[1 \overline{1} 2]$ is the twinning dislocation on (111) plane and $1 / 6[011]$ is the stair-rod (residual) dislocation on (100) plane. It is anticipated that

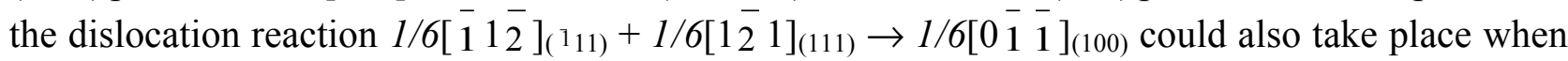
the twin lamella impinges onto the lamellar interface. This reaction again results in the formation 
of $1 / 6\left[\begin{array}{lll}0 & \overline{1} & \overline{1}\end{array}\right]$ stair-rod dislocations on the interface. The formation of stair-rod dislocations at the junctions between $D T$ and lamellar interface is demonstrated in Fig. 6, where the array of 1/6[011] stair-rod dislocations becomes invisible [Fig. 6 (left)] and/or visible [Fig. 6 (right)] when the reflection vectors $(\mathbf{g})$ of 200 and/or 012 are used for imaging. Note that the stair-rod dislocations can not be resolved individually because of an extremely short distance $(0.25 \mathrm{~nm})$ between stairrod dislocations.

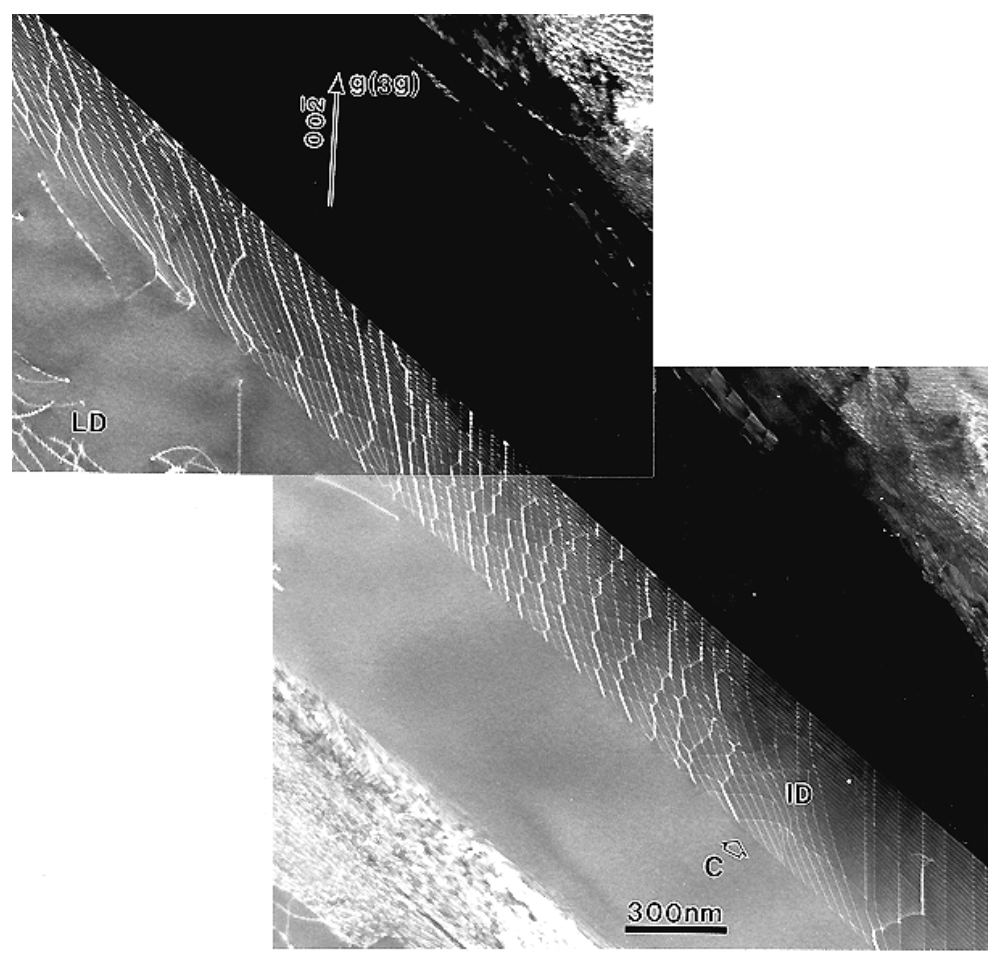

Fig. 4 A WBDF image showing that the motion of interfacial dislocations is impeded as a result of the formation of dislocation nodes (junctions) due to the reaction between impinged $L D$ (stronger contrast) and intrinsic $I D$ (weaker contrast).
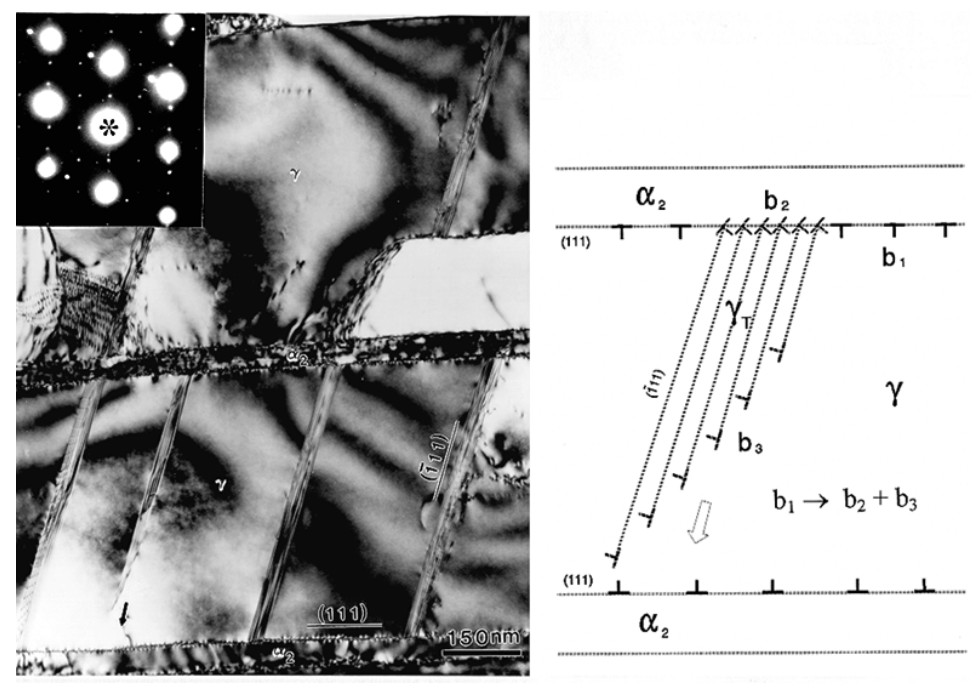

Fig. 5 (Left) A bright-field TEM image showing several ( $\overline{1} 11)$ type $D T$ formed within $\gamma$ lamellae. Notice that one of the twin lamellae was growing between two lamellar interfaces (marked by an 
arrow). (Right) Schematic illustration of the nucleation of a ( $\overline{1} 11)$ type $D T$ from a $\gamma / \alpha_{2}$ interface, where $b_{1}, b_{2}$, and $b_{3}$ denote the interfacial, stair-rod, and twinning dislocations, respectively.

Based on the above observations, it is proposed that the twinning process activated by the pileup of $I D$ is the dominant creep mechanism in the $H S$ regime. In this case, the creep rate $(\dot{\varepsilon})$ may be, in principle, expressed by

$$
\dot{\varepsilon}=M(\dot{N} \cdot \Delta \mathrm{t}) L b \bar{v}
$$

where, $M$ is the number of twin sources per unit volume, $(N \bullet \Delta \mathrm{t})$ is the number of twinning dislocations emitted from a twin source, $L$ is the length of twinning dislocation, $\mathrm{b}$ is the length of Burgers vector, and $\bar{v}$ is the average velocity of twinning dislocation. Quantitatively, $M, \dot{N}$, and $\bar{v}$ in the equation are dependent upon the applied stress and initial microstructure. A rigorous quantitative creep model based upon the twinning process is currently underway.
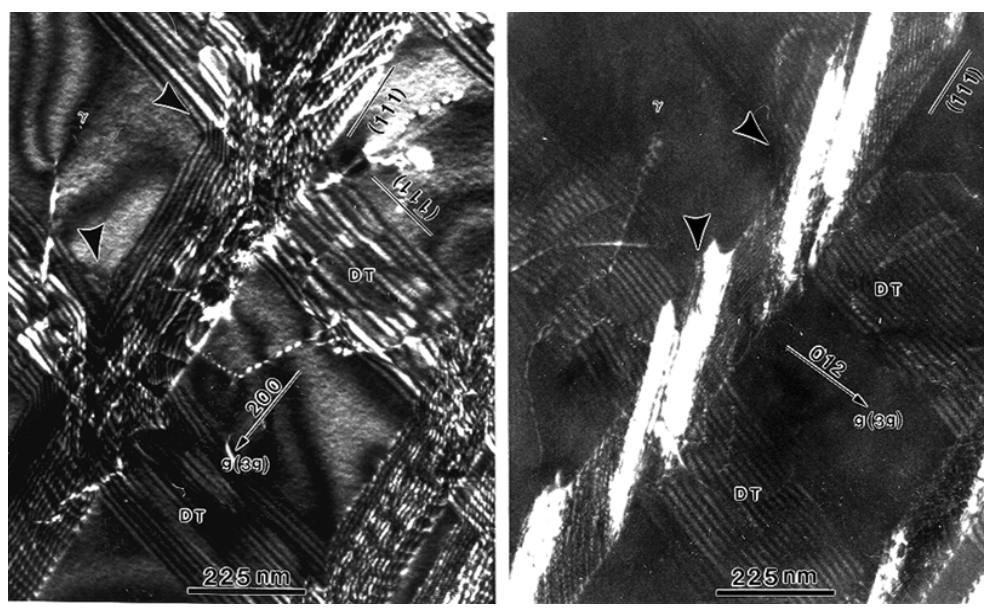

Fig. 6 Paired WBDF images showing the existence of 1/6[011] stair-rod dislocations at the intersections (indicated by arrows) between the (111) type $D T$ and a $\alpha_{2}$ lamella. (Left) Invisible at $\boldsymbol{g}=200(\boldsymbol{g} \bullet \boldsymbol{b}=0),($ right $)$ visible at $\boldsymbol{g}=021, \mathbf{Z}($ zone axis $) \approx\left[\begin{array}{lll}0 & 1 & 2\end{array}\right]$.

\section{Summary}

Creep mechanisms of $F L$-TiAl with a refined lamellar microstructure ( $\gamma$ lamellae: $100 \sim$ $300 \mathrm{~nm}$ thick, $\alpha_{2}$ lamellae: $10 \sim 50 \mathrm{~nm}$ thick) have been investigated. In the low stress regime $(<$ $400 \mathrm{MPa}$ ). the motion and multiplication of lattice dislocations are limited because the refined lamellar spacing, a cooperative motion of interfacial dislocations (i.e. interface sliding) is proposed to be the dominant deformation mechanism. During the sliding of lamellar interfaces, the motion of interfacial dislocations is interrupted by the impinged lattice dislocations on the interfaces and results in the pileup of interfacial dislocations. This is a prevalent process especially at high stresses. To relieve stress concentration at the head of dislocation pileup, ( 111$)$-type deformation twins are observed to emit from the interfaces through the dissociation reaction of interfacial dislocations: $1 / 6\left[\overline{1}^{-} \overline{1}_{\mathbf{}^{111)}} \rightarrow 1 / 6[011]_{(100)}+1 / 6[\overline{1} 1 \overline{2}]_{(11)}\right.$. It is thus suggested that deformation twinning activated by the pileup of interfacial dislocations is the dominant deformation mechanism in the high stress regime $(>400 \mathrm{MPa})$. 


\section{Acknowledgment}

This work was performed under the auspices of the U.S. Department of Energy by Lawrence Livermore National Laboratory under contract No. W-7405-Eng-48.

\section{References}

1. Y -W. Kim, Acta Metall. Mater. 40, 1121 (1992).

2. J. N. Wang, A. J. Schwartz, T. G. Nieh, C. T. Liu, V. K. Sikka and D. R. Clemens, in Gamma Titanium Aluminides, ed. Y-W. Kim et al., TMS (1995), p. 949.

3. J. Beddoes, W. Wallace and L. Zhao, Intr. Mater. Rev., 40, 97 (1995).

4. C. T. Liu, P. J. Maziasz and J. L. Wright, Mat. Res. Soc. Symp. Proc., 460, 83 (1997).

5. T. A. Parthasarathy, M.G. Mendiratta and D.M. Dimiduk, Scripta Mater., 37, 315 (1997).

6. L. M. Hsiung and T. G. Nieh, Mater. Sci. Engrg., A239-240, 438 (1997).

7. L. M. Hsiung, A. J. Schwartz and T. G. Nieh, Scripta Mater. 36, 1017 (1997).

8. J. N. Wang and T. G. Nieh, Acta Mater., 46, 1887 (1998).

9. H. Mehrer, W. Sprengel and M. Denkinger, in Diffusion in Ordered alloys, Eds. B. Fulta et al., TMS (1993), p. 51.

10. W. Sprengel, N. Oikawa, H. Nakajima, Intermetallics, 4, 185 (1996).

11. H. Oikawa, in High Temperature Aluminides and Intermetallics, Eds. S. H. Whang et al., TMS (1989), p. 353.

12. Y. A. Chang, R. Kieschke, J. DeKock and M. X. Zhang, in Control of Interfaces in Metal and Ceramics Composites, edited by R. Y. Lin and S. G. Fishman, TMS (1993), p. 3.

13. C. R. Brooks, in Metals Handbook (Desk Edition, 1985), edited by H. E. Boyer and T. L. Gall, ASM (Metals Park, OH), 28•66(T).

14. R. N. Shenoy, J. Unnam and R. K. Clark, in Oxidation of Metals, 26, 105 (1986).

15. A. I., Nakonechnikov and L. V. Parlinov, Diffusion Data, 6, 573 (1972).

16. C. T. Liu, P. J. Maziasz, and D. J. Larson, in Interstitial and Substitutional Solute Effects in Intermetallics, Eds. Baker et al., TMS (1998), p. 179.

17.J. Weertman and J. R. Weertman, Elementary Dislocation Theory, Macmillan, NewYork (1964).

18. J. P. Hirth and J. Lothe, Theory of Dislocations, McGraw-Hill, New York (1968).

19. J. D. Eshelby, F. C. Frank and F. R. N. Nabarro, Phil. Mag. 42, 351 (1951).

20. T. Mori and H. Fujita, Acta Metall., 28, 771 (1980).

21. M. H. Yoo, Scripta Mater., 39, 569 (1998). 